\title{
Information technology implementation in service enhancement: a qualitative case study
}

\author{
Michael R. Johnson* \\ School of Healthcare Sciences, Cardiff University, Cardiff, United Kingdom
}

Received: August 28, 2015

Accepted: January 11, 2016

Online Published: March 3, 2016

DOI: $10.5430 /$ jnep.v6n7p67

URL: http://dx.doi.org/10.5430/jnep.v6n7p67

\begin{abstract}
The article presents a qualitative case study of the complexities involved in information technology (IT) implementation through illuminating the methods used by two different nurses in the same service enhancement initiative. The importance, relevance and history of learning IT skills is introduced and qualitative case study is argued to be a suitable methodology for investigating and unlocking such social phenomena. Three interviews were conducted and the data combined into a single narrative. One of the participants is very familiar with IT yet reverts to paper for managing numerical data arising from a waiting times audit. This project is taken over by a second nurse who immediately replaces the paper method with a spreadsheet, with help from a service enhancement champion, the third individual interviewed. The circumstances and implications of the nurses' decisions, to avoid or deploy IT, are briefly discussed. The paper concludes that it is unrealistic to expect all nurses to be extremely fluent with IT. However, the decision to leverage IT for innovation and improvement in clinical settings is made easier if education has provided nurses with a firm conceptual and practical foundation.
\end{abstract}

Key Words: Health information technology, Staff development, Quality improvement, Qualitative research, Case study, Nurse education, Technology implementation

\section{INTRODUCTION}

Although students arrive in Higher Education today with some capability with Information Technology (IT), for Sinclair \& Gardner ${ }^{[1]}$ healthcare professionals need to be "more than merely competent" (p.1449), “...they must be capable of upgrading their skills as the technologies and their applications continue to improve and change." Building a case for why they should do this is easier for some aspects of IT than others, and this varies by context. While yet students, the requirements of their programme of study provide a straightforward link with the relevance of improving word processing, presentation and Internet search skills. The relevance of these same skills in clinical areas is less clear though and students may encounter a range of more or less conducive environments for the application or development of IT skills. ${ }^{[2,3]}$

In Australia, Eley et al.' ${ }^{[3]}$ survey found that spreadsheets, along with databases and patient management systems, were the least taught at pre-registrant levels and the most used post-registration, requiring the most training then also. When qualified, nurses may need to use spreadsheets occasionally, e.g., to collate data while auditing an aspect of clinical practice or managing departmental workflow. Perhaps this is the most appropriate timing for such learning. Accountancy students in Selwyn's ${ }^{[4]}$ study expected to learn working-context computer applications when in a job, rather than when in higher education. Ip et al. ${ }^{[2]}$ identified the importance of temporal proximity between training in these skills and their

*Correspondence: Michael R. Johnson; Email: johnsonmr1@ cardiff.ac.uk; Address: Ty Dewi Sant, Heath Park, Cardiff, United Kingdom. 
use in order to retain or develop them, such 'skill decay' ${ }^{[5]}$ is to be expected.

Approaches to learning IT have evolved in phases since its emergence as a subject in the 1970's. According to Martin, ${ }^{[6]}$ in higher education IT has shifted from an 'application focus', emphasising practical knowledge of, for example, programs such as word-processing, spreadsheet or presentation software, towards notions of literacy or fluency, with less emphasis on decontextualized knowledge and towards greater degrees of contextual relevance since the mid 1990's. Martin denotes this the 'reflective phase' in which it is assumed that basic facility with IT may be taken for granted. While this might seem sensible, even progressive and 'learner centred', more recent research highlighted the way that this kind of approach to learning IT left learners with gaps in confidence and capability. ${ }^{[7]}$ The present case study aims to illustrate that gap through its depiction of two nurses who represent learners from two different educational experiences, in particular with regards to IT.

\section{Methodology}

In spite of, or perhaps because of, decades of empirical and theoretical work relating directly to 'case study', it remains an ambiguous and contested concept. ${ }^{[8]}$ Stake $^{[9]}$ asserts that a case study need not answer the 'a case of what?' question. The 'intrinsic' study may be of a case that is interesting enough in its own right.

In a sense, an investigation into the history and status of 'case study' provides an illuminating case of the contested nature of research methodologies in general. Robert Yin's ${ }^{[10]}$ pluralistic stance holds that variations in philosophical beliefs, purpose, and product merely highlight the similarities between all that goes by the name of case study. However, Thomas ${ }^{[8]}$ sides with George and Bennett ${ }^{[11]}$ who brand the likes of Yin as neopositivists, who "espouse the interpretivist holism of case study but address this... via the identification of variables to be studied". ${ }^{[8]}$ For Mason, most qualitative researchers have "rejected the logic of variable analysis". ${ }^{12]}$ Thomas, in his discussion of subject and object in case study, also raises concerns about the conceptual slippage involved in borrowing terms from the positivist paradigm. He cites Ragin, ${ }^{[13]}$ who, with Hammersley, ${ }^{[14]}$ see case study as contrasting with variable-led research in terms of the focus on few variables amidst a large sample versus many factors in few cases. This may be analytically fair, but, in the process, opens up the possibility that case study is different by degree, rather than category. After Law and Urry, ${ }^{[15]}$ as the 'social' is 'enacted', it can distract and detract from the mission of qualitative case study; as Helen Simons has noted, ${ }^{[16]}$ urging researchers to attend to the reasons why case study came to prominence in the 1970's, when experimental educational research proved inadequate for evaluating complex educational innovation. In addition, case study gave participants more of a voice, it engaged "readers of the reports with the veracity of experience of the programme", and, with the data being more open, complex and multi-voiced, case study offered, "...to increase their understanding of the programme to inform judgements that they needed to make. In other words, it rendered policy making uncertain". ${ }^{[16]}$ In spite of this last 'flaw', or rather because of it, Simons calls researchers to take "creative courage" [17] and embark on...

the intuitive, holistic process of analysing case study data... The search for certainty, comparison and conclusiveness tends to drive out alternative ways of seeing. Yet it is the latter, I have argued, which offer us new insight and potentially that quantum leap in understanding which may change our worlds (No Page). ${ }^{[16]}$

In approaching this study, I have tried to adopt that 'alternative way of seeing', at least to allow for complexity to emerge and exist through the case narrative. Part of 'staying open' requires a 'closing off' from the lure of pursuing certainty. For Simons ${ }^{[16]}$ the aim of 'portrayal rather than analysis' must not be blurred. Thomas' ${ }^{[8]}$ insistence in identifying a clear subject and object within the case study must be resisted, at least initially. Van Wynsberghe and Khan's slant on case study as heuristic is helpful here: that...

through detailed description the researcher is further enabled to uncover, delineate, or construct the unit of analysis among a number of potential candidate units of analyses. Once the unit of analysis is clear, the case study can reveal its central message (p.6). ${ }^{[18]}$

Ragin even assures us that, vis-à-vis the unit of analysis, "the less sure that researchers are of their answers, the better their research may be". [13] The researcher as reflective learner must sustain a sense of "perplexity, hesitation, doubt"[19] in the pursuit of their enquiry. As the enquiry matures, that learning ripens for sharing. It is hoped that this case study of nurses using spreadsheets could act as a cautionary tale to the profession, using the familiar channel of storytelling, a common and accepted medium for conveying inter-generational values that underpin nursing identity, ${ }^{[8]}$ promoting a conception of nursing's professional trajectory that includes the creative exploitation of IT as a norm, not something to shy away from. After all, IT is a fundamental toolset for improving the quality of care and its delivery. ${ }^{[20]}$ 


\section{METHOD}

The study aimed to produce a narrative through combining accounts obtained in semi-structured interviews. Cohen $e t$ $a l^{[21]}$ are supportive of narrative analysis because it... retains the integrity of people rather than fragmenting bits of them into common themes or codes, it enables evolving situations, causes and consequences to be charted. It enables events to 'catch fire' as they unfold. Narratives are pow- erful, human and integrated; truly qualitative (p.554).

A list of questions (see Table 1: Interview questions) was developed to help guide the interview and facilitate gathering fairly 'broad brush' accounts of each participant's personal history, experiences and opinions of IT, etc. Three individuals were selected because of their proximity to the case, as initially conceived.

Table 1. Interview questions

\begin{tabular}{|ll|}
\hline 1) & Please could you say a bit about your work and role within the organisation? \\
2) Can you say a little about how you came to work here? \\
3) Tell me a bit about your experience with computers? \\
4) Have you had any training with computers in the last few years? How effective was that? \\
5) How have you learned to use spreadsheets? \\
6) How much expertise do you have with spreadsheets? Before and after your/any training? \\
7) Do you use spreadsheets in your work? For what kinds of things? \\
8) What kinds of things do spreadsheets get used for? Do you have a recent example? \\
9) How much is enough knowledge of spreadsheets? \\
10) So could you summarise, what do you think that nurses need to know about spreadsheets?
\end{tabular}

All three are in their 'middle years', having qualified before their respective professions became exclusively 'degree entry'.

- Ahmad: a nurse, recently returned to the outpatient clinic after a prolonged illness.

- Martin is an OT (Occupational Therapist) with a track record for deploying information management skills in service enhancement.

- Sai Li: a nurse who also manages the outpatient clinic.

Although other more peripheral individuals could conceivably have made a significant contribution, it was hoped that the three would provide an "adequot" of data ${ }^{[22]}$ to generate "thick description".[23]

Ethical approval for the study was granted by Lancaster University's Department of Educational Research who classified the research as "low risk". Nevertheless, the ethical faultlines of data collection and dissemination of findings for case study research, as identified by Merriam, ${ }^{[24]}$ were taken very seriously. Names and sexes of participants have been changed. The process of ethical governance to access National Health Service (NHS) staff for participation in research is bureaucratic, thus gaining approval is impractical at short notice and for small-scale studies. Therefore each participant agreed to be interviewed outside working hours. An information sheet and consent form was sent by email to each participant well before their interview. Participants agreed to meet individually at a location of their choice. The meeting began with a further opportunity to scrutinise and question the information sheet and complete the consent form. The interviews were recorded, each lasting around an hour and were transcribed verbatim. Recordings and transcripts were reviewed repeatedly to obtain clarity and familiarity with the accounts before they were framed into a single narrative.

\section{THE CASE}

The three individuals interviewed for this study had three different levels of awareness of spreadsheets. Ahmad had not used spreadsheets since his degree studies, 20 years ago: "when I graduated people didn't have their own computers, very few people did." He had taken IT and statistics modules as part of the degree: "I think I was being taught IT at University almost as early as IT was being taught at university."

...then I did a dissertation where I collected a lot of data using questionnaires and I knew that I could input the data into a spreadsheet and that I could make calculations and display the information in a meaningful way using spreadsheet and I had some help from a member of the Department that I was working in and we use this package called SPSS. Ahmad

Ahmad was "quite qualified for my age" (mid 40's), but a series of "life events" had stilted his career progression. Around the turn of the 21st Century nursing began its transition into an all graduate profession. Ahmad and Sai $\mathrm{Li}$ 
represent a cadre of nurses who qualified before a degree was needed and before IT was established as an essential part of school-age education in the UK.

That is not to say that $\mathrm{Sai} \mathrm{Li}$ is averse to IT, even if she has to endure the family's teasing her lack of technological prowess:

My guys here, and husband, take the Mickey out of me because, "oh don't let her touch the computer because it'll break", but then they don't see what I get up to in work, you know I'm doing all sorts on there, obviously answering emails on a daily basis, doing the check pay cards, and all sorts of um, you know, things we deal with. And similarly with the nurse led clinic, you're in and out of patient's notes looking at charts, you're looking at, um, previous history, you're looking at treatment plans and things. So they have no idea. I'll let them think that way. Sai Li

Sai Li's use of these systems is well supported by regular training updates but the lack of a firm foundation leaves her with a sense that she doesn't know what she doesn't know. Clerical staff and her children have showed her, as she says,

... a whole range of things on the computer... which really you know, you feel that, if you had that knowledge you could perhaps do it in the workplace, but it's just about, trying to find your deficit and matching it really, but I think that, erm, you know, certainly for me, the structured computer programming teaching, we haven't had a great deal of it, and it's just really learning as and when you go along. Sai $\mathrm{Li}$

This in spite of a project to bring all staff in the National Health Service up to 'European Computer Driving Licence' level. ${ }^{[25]}$ Ahmad and Sai Li expressed dissatisfaction with the way this was delivered. Typically, nurses only studied three of the seven exams, missing out word processing, spreadsheets, presentations and databases. Even then,

...it wasn't as good as I thought it might be, and in fact, um, for nursing they expected you to do one particular module on one day and do the exam the same day... Didn't give you time to go back and put that into practice first, um, that wasn't the best way of learning, you know, I felt, whereas, admin staff, some of the admin staff I know, had a longer time to do a couple of sessions and then sit the tests. So I don't know whether it was they were trying to fast track us all through, because of course technology is going to be more part part of our job, but it wasn't the most um structured way of learning. I've got an ECDL certificate, but it's modules 1, 2 and 7, I can't remember what they were now... Sai $\mathrm{Li}$

In contrast, as for Ahmad, Sai Li's recently completed parttime Bachelor of Science degree provided a significant arena for learning and practicing computer skills. After initially being frightened by the university's online systems, she quickly adjusted and grew in confidence to the extent that this transferred into the workplace. Sai Li's degree focussed more on the use of research than the generation of new knowledge, so there was less opportunity or reason to learn data collection and handling skills than for Ahmad.

Ahmad was returning to work in Sai Li's department on a phased basis following a lengthy absence. The requirement to ease him back gradually into aspects of work involving direct contact with service users provided an opportunity for Sai Li to delegate some of her office-based work to Ahmad. An audit of waiting times was already underway in response to an executive request for all departments to propose an area for improvement. As Ahmad explained,

There's a huge footfall into the clinics each week and so there's a lot of processes that they have to go through, so requires sitting around waiting but a lot of the other aspects of their time in clinic they are very happy with, but this is the one thing that they repeatedly say so and the manager of the Department decided to actually find out to begin with how much waiting was going on, so once a month for a whole week the nurses were recording the time lapse between them arriving in the departments or the time of their appointments, more importantly the appointment that they'd been given to turn up at and the time that they'd waited to see a clinician and that was marked against their appointment time. So Mr Brown is expected in the Department at 9 o'clock and duly arrives, and then maybe isn't seen until 10:10, so next to the 9 o'clock appointment time is noted "10:10". So at the end of the week of recording each patient's actual waiting time, the person recording the data and looking at the results would work out how much each patient had waited in each clinic, and then for each clinic would calculate an average waiting time. And that has been done for about three months when I got back... Ahmad 
Sai Li had completed a similar audit the previous year. That time she was helped by administrative support staff who transferred the paper-based records into a spreadsheet. With his knowledge of data management, Ahmad describes picking up from Sai Li this time:

...instead of putting all the data into a spreadsheet they would transfer the waiting times of each patient onto a piece of paper and do a calculation to work out the mean waiting time of different clinics but what.., and so I thought it would be much less labour-intensive if the information was fed into a spreadsheet and then you would have it recorded and you could use the data in different ways including to calculate means and other calculations and to and to produce graphs from it rather than copying things from paper to paper... and then but I didn't have a lot of knowledge of how the spreadsheets worked because I hadn't use them for nearly 20 years and I just knew that it could work so then I contacted somebody who had more knowledge and he's actually shown me there are better ways to represent this information and I'm going to go on a course in a while to learn more about that for myself. Ahmad

The course leader is Martin, with over 15 years of experience as an occupational therapist. Like Ahmad and Sai Li, his qualification to practice was gained before degrees were tied in with professional registration. It was not until 2008, when Martin moved into a managerial role, that he was confronted with the requirements of working with data...

and started having to think about matters such as capacity and demand and all the service enhancement stuff, numbers of patients, it was a self-learning situation really, erm, because I had absolutely no idea whatsoever, I had no clue about Excel and Excel is the tool that I use all the time so you know, I got myself onto some internal courses... but in general, you know, if you don't use it, as soon as you've been on the course you forget it quite quickly. So I have found that, over the years, I've just self-taught, really in order to produce the stuff that I now produce. Martin

From his vantage-point in the organisation, Martin can envisage constellations of people, technologies and processes, with great potential to make significant improvements in the service, dangling isolated, frustratingly disconnected or out of reach of each other... Published by Sciedu Press
There is no way of logging electronically when the patient sees a doctor so that has to be captured manually. I find that hard to believe, but that's what I'm told by our hospital support people. But you know, that's the sort of problem that we face. Erm, and it just could be so different [laughing]. So then, instead of staff having to collect data manually and input it into an Excel spreadsheet, you know, just to have a report out, so then we'd get over the having to collect the data... it's then going straight into, "okay we've got this data, how do we analyse it?". But we haven't even got the stuff in there electronically. Martin

Even if staff wanted to develop the service through information, they face a dysfunctional assemblage of people and parts, ${ }^{[26]}$ each one damping the pace of progress. In these circumstances, without a very high 'threshold of indignation, ${ }^{[27]}$ staff fall off from using digital technology, and fall back on the familiar:

So it, it it, just puts it in the, "too difficult" category which is a shame. You know, all the ideas for improvement come from the staff who are doing the work, they're the ones that know how things could be improved. But, it's not necessarily something that you can do instantly or ask them to do instantly, because it will always go back to paper and then having to put it in to the computer. Martin

Working within his sphere of influence, Martin has a strategic objective to put all staff through training to narrow the conceptual leap for "staff who are doing the work", giving them the ability to think in the abstract about how ideas can be shaped up into an improvement.

Once they've actually seen what they need to do and and use the software that we give them then they start producing some lovely stuff, but it's just getting over that hump y'know, people are frightened of, of data, and spreadsheets, and stuff like that... It's just unfamiliar, it's just not something that they do in their day-to-day jobs. Martin

Although Ahmad had significantly more spreadsheet background and insight than Sai Li, Ahmad still struggled with the question of how to represent the data and, after speaking with Martin about it, had to re-input pages of time-based entries so that they could be used in calculations and to create graphs. 
So, you know, there has to be a knowledge of what Excel expects so, you know, if you need to have that knowledge then surely it's just a sensible step that you're able to actually produce the graphs. Because otherwise anyone could put numbers in a spreadsheet but you can't do a thing with them. So it's got to be meaningful and it's got to be in terms of what Excel recognises, because it's a funny old beast! [laughs]

Frequently you don't realise how a spreadsheet can help you. You know, this is what I mean about, having to work it out in your head really, as to how it could be beneficial, and if you have no knowledge of of them whatsoever then you are starting from a very low point. Martin

\section{Discussion}

Zechariah et al. ${ }^{[28]}$ conclude their recent review with a call for nurses to be educated in 'informatics competencies so that technology can be embraced as a tool in everyday practice' (p9). However, this case study implies that the answer lies deeper than competency training.

Ahmad had made the straightforward, even obvious, choice to abandon Sai Li's laborious paper-based data handling in favour of using spreadsheet software. What is more curious was Sai Li's prior decision not to use a spreadsheet for this work. Even though Ahmad was not capable of undertaking the spreadsheet-based audit without additional help, based on his long distant undergraduate degree, he remembered the "kinds of things" spreadsheets could be used for, having applied the IT training at university in empirical work for his final year dissertation. Ahmad's spreadsheet "skill decay" meant that he was not able to make good use of a spreadsheet, but at least he did make the right choice to use the spreadsheet and consult Martin when he got stuck. The IT components, including the latter empirical work, in Ahmad's undergraduate degree were thus transformative, even after very large gaps in time. Although Ahmed may not be described as a particularly 'literate' or 'fluent' user of IT, yet there are signs here of what Shah, ${ }^{[29]}$ in a learning technology context, has termed 'omnipotential'. Technology was used as a...

means and tool for numerous possibilities and opportunities that may be difficult otherwise. The teachers described using it in multiple ways ranging from its real-time use in classrooms to information collection and research activities to collaboration with the academics and institutions outside... (p.95)
In contrast, Sai Li used IT fluently, with flair even, on a daily basis. Thus her choice not to use a spreadsheet for the audit data remains a paradox. How had Sai Li not acquired insight of the awareness of spreadsheets to facilitate the work of the audit? How has the vaunted implementation of ECDL training fallen so far short of meeting the needs of staff like Sai Li? What policy decisions have been made that leave her without the resources to do her job effectively? The epistemic limits placed upon Sai Li's far more recent degree curriculum meant that she was never required to develop the skills associated with empirical research. The United Kingdom's governing body, the Nursing and Midwifery Council (NMC), specifies that undergraduate pre-registration nursing programmes should prepare nurses as research users, rather than generators of new knowledge. ${ }^{[30]}$ In passing, note that this limitation is in tension with contemporary aims for learners to be "producers rather than consumers of knowledge". [31] It also pitches meaningful spreadsheet use by nurses well past graduation and on into qualified nursing practice. When even students much younger than Ahmad and $\mathrm{Sai} \mathrm{Li}^{[30]}$ 'perceived that they had little knowledge when it comes to... using a spreadsheet such as Excel', amongst other things (p744), it makes calls for 'more than competence ${ }^{\text {' }}{ }^{[1,28]}$ seem over-optimistic. There is a the tension between the need for the training and application of skills to retain them, but also the paucity of opportunities to achieve that in college or clinical practice. ${ }^{[2]}$ Alexander's ${ }^{[31]}$ 'Applied Clinical Informatics for Nurses' treatment of spreadsheets is cursory at best and does not even mention the word 'data'. Yet a Google Scholar search for 'nursing' AND 'spreadsheets' shows that spreadsheets are in regular use for various stages of data collection, analysis and presentation, all of which could feature in the latter stages of a degree, especially the dissertation. This is the kind of empirical knowledge work that supported Ahmad's clinical audit.

\section{Conclusion}

This qualitative case study has sought to illuminate something of the complex circumstances surrounding what could be termed a "non-decision", i.e., to shy away from using a suitable IT tool and use paper and pencil instead. This was in spite of many factors which might have led one to expect the contrary. It may be obvious that using spreadsheets can increase one's efficiency and accuracy when handling numerical data. This consequentially opens up opportunities to marshal quantitative data, for example, as part of a service enhancement initiative. But is it realistic to aspire to a time when all nurses achieve and maintain high levels of IT fluency? It may be better to lay a solid foundation in IT at undergraduate level, both practical and conceptual, and to en- 
sure that supportive staff, such as Martin, with thoroughgoing working knowledge of the software, are accessible to guide those who are almost subconsciously aware of IT's potential

\section{REFERENCES}

[1] Sinclair M, Gardner J. Planning for information technology key skills in nurse education. Journal of Advanced Nursing [Internet]. 1999; 30(6): 1441-1450. http://dx.doi.org/10.1046/j.1365-264 8.1999.01218.x

[2] Ip B, Jones S, Jacobs G. Retention and application of information technology skills among nursing and midwifery students. Innovations in Education and Teaching International [Internet]. 2007; 44(2): 199-210. Available from: http://www.tandfonline.com/ doi/abs/10.1080/14703290701241018 http://dx.doi.org $/ 10.1080 / 14703290701241018$

[3] Eley R, Fallon T, Soar J, et al. The status of training and education in information and computer technology of Australian nurses: a national survey. Journal of Clinical Nursing. 2008; 17(20): 2758-2767. Available from: http://onlinelibrary.wiley.com/doi/10.1111/ j.1365-2702.2008.02285.x/abstract PMid:18808645 http: //dx.doi.org/10.1111/j.1365-2702.2008.02285.x

[4] Selwyn N. Understanding students (non) use of information and communications technology in university. 2003. Available from: http://www.cardiff.ac.uk/socsi/research/publi cations/workingpapers/paper-40.html

[5] Arthur Jr. W, Bennett Jr. W, Stanush PL, et al. Factors That Influence Skill Decay and Retention: A Quantitative Review and Analysis. Human Performance. 1998; 11(1): 57-101. Available from: http://search.ebscohost.com/login.aspx?direct $=$ true $\& \mathrm{db}=$ buh $\& A N=7308508 \&$ s $i$ te $=$ ehost - live

[6] Martin A. Concepts of ICT Literacy in Higher Education. University of Glasgow; 2002. Available from: http://www.citscapes.ac.uk/citscapes/produc ts/backgroundreports/files/concepts_ict_HE.pdf http://dx.doi.org/10.1207/s15327043hup1101_3

[7] van Dijk JAGM, van Deursen AJAM. Digital Skills: Unlocking the Information Society. Palgrave Macmillan; 2014.

[8] Thomas G. A Typology for the Case Study in Social Science Following a Review of Definition, Discourse, and Structure. Qualitative Inquiry. 2011; 17(6): 511-521. Available from: http://qi $\mathrm{x}$. sagepub. com/content/17/6/511 http://dx.doi.org/10. $1177 / 1077800411409884$

[9] Stake RE. Case Studies. In: Denzin NK, Lincoln YS, editors. The Sage handbook of qualitative research. 2nd ed. Thousand Oaks, CA: Sage Publications Ltd; 2000. 435-455 p.

[10] Yin RK. Case study research: design and methods. 2nd ed. Thousand Oaks: Sage Publications; 1994.

[11] George AL, Bennett A. Case studies and theory development in the social sciences. Cambridge, Mass.; London: MIT Press; 2005.

[12] Mason J. Qualitative researching. London; Thousand Oaks, Calif: Sage; 1996.

[13] Ragin CC. Introduction: Cases of "What is a case?" In: Ragin CC, Becker HS, editors. What Is a Case: Exploring the Foundations of Social Inquiry. Cambridge University Press; 1992. 1-18 p.

[14] Hammersley M. What's wrong with ethnography: Methodological Explorations. London: Routledge; 1992. for helping them enhance care, systems and services.

\section{CONFLiCTS OF INTEREST Disclosure}

The author declares that there is no conflict of interest.
[15] Law J, Urry J. Enacting the social. Economy and Society. 2004; 33(3): 390-410. Available from: http://www.tandf online.com/ doi/abs/10.1080/0308514042000225716 http://dx.doi.o $\mathrm{rg} / 10.1080 / 0308514042000225716$

[16] Simons H. The paradox of case study. Cambridge Journal of Education. 1996 Jun; 26(2): 225. http://dx.doi .org/10.1080/030 5764960260206

[17] May R. The Courage to Create. W. W. Norton; 1994.

[18] Van Wynsberghe R, Khan S. Redefining Case Study. International Journal of Qualitative Methods. 2007; 6(2): 1-10. Available from: http://search.ebscohost.com/login.aspx?di rect $=$ true $\& d b=a 9 h \& A N=25730127 \&$ site $=$ ehost - live

[19] Dewey J. How We Think. 1910. Available from: http://www.gu tenberg.org/ebooks/37423

[20] Porter-O'Grady T, Malloch K, editors. Innovation leadership: creating the landscape of health care. Sudbury, MA: Jones and Bartlett Publishers; 2010

[21] Cohen L, Manion L, Morrison K. Organizing and Presenting Qualitative Data. Research Methods in Education. 7th ed. Oxon: Routledge; 2011. 537-558 p.

[22] Atkinson P. Keynote. Cardiff; 2015. Available from: http://www . cardiff.ac.uk/news/view/142132-after -paul-atkinson-the-future-of-three-research-areas

[23] Geertz C. The Interpretation of Cultures: Selected Essays. Basic Books; 1973.

[24] Merriam SB. Case study research in education: a qualitative approach 1st ed. San Francisco: Jossey-Bass; 1988.

[25] ECDL Foundation. ECDL/ICDL Computer Essentials Syllabus Version 1.0. 2012. Available from: http://www.ecdl.org/media/C omputerEssentials2.pdf

[26] Latour B. Reassembling the social: an introduction to actor-network theory. Oxford; New York: Oxford University Press; 2005.

[27] Saffo P. The Consumer Spectrum. In: Winograd T, editor. Bringing Design to Software. New York, N.Y. Reading, Mass.: ACM Press; Addison-Wesley; 1996.

[28] Jebakumar AZ, Nondo HS, Sarfo SK. Challenges of nursing informatics-a critical review. European Journal of Nursing. 2014; 1(1): 6-10. Available from: http://mcmed.us/downloads/ejn_518032523 8.pdf

[29] Shah U. Teachers' use of learning technology in a South Asian context. In: Hodgson V, de Laat M, McConnell D, Ryberg T, editors. The Design, Experience and Practice of Networked Learning. 2014 edition. New York: Springer; 2014. 87-105 p.

[30] Jetté S, Tribble DS-C, Gagnon J, et al. Nursing students' perceptions of their resources toward the development of competencies in nursing informatics. Nurse Education Today [Internet]. 2010 Nov; 30(8): 742-746. Available from: http://www. sciencedirect.com/sc ience/article/pii/S0260691710000286 PMid:20362369

[31] Alexander S, Frith K, NEA-BC, et al. Applied Clinical Informatics for Nurses. Jones \& Bartlett Publishers; 2014. Available from: http://books.google.co.uk/books?id=A95bAwAAQBAJ\&l $\mathrm{pg}=\mathrm{PR} 1 \& \circ \mathrm{ts}=\mathrm{qbU}-\mathrm{srfnrc \& dq=}$ urses$\% 20$ spreadsheet $\mathrm{s} \& \mathrm{lr}=$ lang_en\&pg $=P A 30 \# v=$ onepage\&q=spreadsheet\&f $=f$ alse 